\title{
Systematic review of published interventions aiming to increase vegetable intakes
}

\author{
KM Appleton ${ }^{1}$, A Hemingway ${ }^{1}$, L Saulais ${ }^{2},{ }_{5}$ C Dinnella ${ }^{3}$, E Monteleone ${ }^{3}$, L Depezay ${ }^{4}$, \\ D Morizet ${ }^{4}$, FJA Perez-Cueto', A Bevan ${ }^{1}$ and $\mathrm{H}^{5}$ Hartwell ${ }^{1}$ \\ ${ }^{1}$ Bournemouth University, Poole, UK, ${ }^{2}$ Institut Paul Bocuse, Ecully, France, ${ }^{3}$ University of Firenze, Florence, Italy, \\ ${ }^{4}$ Bonduelle, Villeneuve D'Ascq, France and ${ }^{5}$ University of Copenhagen, Copenhagen, Denmark
}

The health benefits of a high fruit and vegetable consumption are well known and considerable current work attempts to improve intakes $^{(1)}$. Fruits and vegetables, however, are separate food groups, that tend to be consumed differently, and tend to be consumed or avoided as a result of different determinants ${ }^{(2,3)}$. Increasing work also suggests health benefits from a high consumption specifically of vegetables, and low vegetable intakes across Western countries, but fruit and vegetable interventions typically tend to have more success for fruit intakes than for those of vegetables ${ }^{\text {(e.g.4) }}$. This study aimed to systematically review the published literature for all studies reporting an intervention to increase intakes of vegetables as a specific food group.

Three databases - PubMed, PsychInfo and Medline were searched over all years of records until April 2015, using with the terms 'vegetable' and 'vegetables' in the 'title'. All searches were conducted, and all titles and abstracts screened for relevance by two independent review authors (KMA, AH or $\mathrm{HH}$ ). Studies were included in the review if they involved an intervention designed primarily to increase vegetable intakes as a specific and distinct food group, and if they intended to change behaviour - vegetable selection, purchasing, or vegetable consumption. We made no attempt to assess study quality, or to combine interventions, e.g. through meta-analysis.

Our searches identified 77 studies, detailing 140 interventions. Interventions aimed to use or change hedonic factors, such as taste, liking and familiarity $(n=72)$, use or change environmental factors $(n=39)$, use or change cognitive factors $(n=19)$, or used a combination of strategies $(n=10)$. A total of $133(81 \%)$ interventions were conducted in children. Of the 140 interventions, $116(83 \%)$ interventions reported increased vegetable selection and/or consumption to some degree. The majority of effects, however, seem small and inconsistent. Greater percent success was found from environmental, educational and multi-component interventions. Publication bias is also likely in this new area of research, and long term effects and cost-effectiveness were rarely considered.

Limited work is currently available assessing the impact of behavioural interventions for increasing vegetable intakes, and further work is required. Interventions should be developed based on the underlying determinants of poor vegetable consumption, and should include long-term and cost-effectiveness assessments. Certain population groups - adolescents, adults, older people and individuals living on a low income are also largely absent from the current list of tried interventions. Further work is clearly needed, and a focus on long-term benefits and sustained behaviour change is required.

1. Woodside JV, Young IS, McKinley MC. Fruits and vegetables: measuring intake and encouraging increased consumption. Proc Nutr Soc. 2013, 72:236- 45 .

2. Glasson C, Chapman K, James E. Fruit and vegetables should be targeted separately in health promotion programmes: differences in consumption levels, barriers, knowledge and stages of readiness for change. Public Health Nutr. 2011, 14:694-701.

3. Trudeau E, Kristal AR, Patterson RE. Demographic and psychosocial predictors of fruit and vegetable intakes differ. Implications for dietary interventions. JADA. 1998, 98:1412-17.

4. Neville CE, McKinley MC, Draffin CR, et al. Participating in a fruit and vegetable intervention trial improves longer term fruit and vegetable consumption and barriers to fruit and vegetable consumption: a follow-up of the ADIT study. Int J Behav Nutr Physical Activity, 2015, 12:158. 